\title{
Türkiye'de orman kaynakları yönetiminin iklim değişikliğine uyumuna ilişkin değerlendirmeler
}

\author{
Mehmet Korkmaz $^{\text {a,* (D), Ozan Arif Adıgüzel }}{ }^{\mathbf{b}}$ (i)
}

\begin{abstract}
Özet: İklim değişikliği gelecek dönemlerde orman kaynaklarını ve ekosistem hizmetlerinin sürekliliğini daha fazla etkileyecektir. $\mathrm{Bu}$ açıdan orman kaynakları yönetiminin iklim değişikliğine uyumunun sağlanması önemli bir gerekliliktir. Bu makalede orman mühendislerinin iklim değişikliğine yönelik bilgi düzeyleri, iklim değişikliğinin orman kaynaklarına etkileri ve uyum süreçleri kapsamında mevcut ve öngörülen ormancılık yönetim ve uygulamalarına yönelik algı ve görüşleri değerlendirilmiştir. Bu kapsamda 241 orman mühendisi ile anket çalışmaları yürütülmüştür. Çalışma sonuçlarına göre, iklim değişikliğinin orman kaynaklarına etkisine ilişkin olası değişimler; biyotik ve abiyotik zararların artacağı ve zamanla tür kompozisyonunda değişikliklerin yaşanacağı şeklindedir. Mevcut ulusal ormancılık politikaları iklim değişikliğinin olumsuz etkilerinin önlenmesi konusunda yetersiz bulunmuş, aynı zamanda mevcut bazı politikaların ormancılık uygulamalarına aktarımının da yeterli olmadığı ve iklim değişikliğine uyumun sağlanması için orman kaynakları yönetiminin değişmesi gerektiği görüşü büyük bir çoğunlukla ifade edilmiştir. Karışık meşcerelerin kurulmasının teşvik edilmesi, ağaçlandırmalarda gelecekteki iklime daha iyi uyum sağlayabilecek türlere yer verilmesi ve orman sağlığının izlenmesi en önemli önlemler olarak öne çıkmıştır.
\end{abstract}

Anahtar kelimeler: İklim değişikliği, Orman kaynakları yönetimi, Orman mühendisleri, Uyum

\section{Evaluations on adaptation of forest resources management to climate change in Turkey}

\begin{abstract}
Climate change will affect forest resources and the continuity of ecosystem services more in the future. In this respect, it is an important requirement to ensure the adaptation of forest resources management to climate change. In this article, the knowledge levels of forest engineers on climate change, the effects of climate change on forest resources and their perceptions and opinions of current and foreseen forestry management and practices within the scope of adaptation processes were evaluated. In this context, survey studies were conducted with 241 forest engineers. According to the results of the study, possible changes regarding the impact of climate change on forest resources; abiotic and biotic damages will increase and there will be changes in species composition over time. Existing national forestry policies were found to be insufficient to prevent the negative effects of climate change, at the same time, it was stated that the transfer of some existing policies to forestry practices was not sufficient, and that forest resources management should be changed to adapt to climate change. In this context, encouraging the establishment of mixed stands, including species that can better adapt to the future climate in afforestation and monitoring forest health have come to the fore as the most important preventions.
\end{abstract}

Keywords: Climate change, Forest resources management, Forest engineers, Adaptation

\section{Giriş}

Sanayi devriminden itibaren fosil yakıtların yoğun bir şekilde kullanılması, ormansızlaşma, arazi kullanım değişiklikleri ve sanayi üretiminin artışı gibi insan temelli etkinliklere bağlı olarak atmosferdeki sera gazı birikimi artmakta ve sıcaklıklar küresel düzeyde yükselmektedir (Türkeş, 2008). Sicaklıkların artışına bağlı olarak iklim koşulları küresel düzeyde değişmekte olup bu değişiklikler önemli düzeyde yerel etkilere yol açmaktadır (Türkeş vd., 2000). İklim değişikliğinin etkilerini azaltma kapsamında atmosferdeki sera gazlarının düzeyini kontrol altında tutma önem arz etmektedir. Ancak sera gazlarının birikimi belli bir düzeyde tutulabilse bile iklim değişikliğinin etkisi, uzun yıllar boyunca devam edecektir. Diğer taraftan, IPCC 5.
Değerlendirme Raporu'nda iklim değişikliğinin etkilerine uyum sağlayabilmek için karşılanacak ekonomik maliyetin, iklim değişikliğinin vereceği zararın maliyetinden çok daha düşük olacağı vurgulanmakta (Silkin, 2014) olup iklim değişikliğine uyumun önemi artmaktadır.

İklim değişikliğine uyum, “doğal sistemlerde veya insan sistemlerinde gerçek veya öngörülen iklim değişikliği ve değişkenliğinden etkilenebilirlik düzeyinin indirilmesini veya firsatlardan yararlanılmasını amaçlayan ayarlamalar" olarak tanımlanabilmektedir (ÇŞB, 2011). Bir başka tanıma göre (Spittlehouse ve Stewart, 2003) ise iklimdeki değişikliklerin etkilerine yanıt olarak ekolojik, sosyal ve ekonomik sistemlerdeki ayarlamalardır. Uyum, toplumun her kesimi ve her bir sektör açısından ayrı ayrı stratejileri ve hedefleri içermektedir. Örneğin “Türkiye'nin İklim

\footnotetext{
$\triangle$ a Isparta Uygulamalı Bilimler Üniversitesi, Orman Fakültesi, Orman Mühendisliği Bölümü, 32260, Isparta

b Isparta Orman Bölge Müdürlüğü, Sütçüler Orman İşletme Müdürlüğü, Isparta

@ * Corresponding author (İletişim yazarı): mehmetkorkmaz@ isparta.edu.tr

$\checkmark \quad$ Received (Geliş tarihi): 05.11.2021, Accepted (Kabul tarihi): 06.12.2021
}

Citation (Atıf): Korkmaz, M., Adıgüzel, O.A., 2021. Türkiye'de orman kaynakları yönetiminin iklim değişikliğine uyumuna ilişkin değerlendirmeler. Turkish Journal of Forestry, 22(4): 417-425. DOI: $\underline{10.18182 / \mathrm{tjf} .1019556}$ 
Değişikliği Uyum Stratejisi ve Eylem Planı”nda (ÇŞB, 2011) uyum; (a) su kaynakları yönetimi, (b) tarım sektörü ve gıda güvencesi, (c) ekosistem hizmetleri, biyolojik çeşitlilik ve ormancılık, (d) doğal afet risk yönetimi, (e) insan sağlığı ve (f) iklim değişikliğine uyum bağlamında yatay kesen ortak konular olarak ayrı ayrı ele alınmış ve planlanmıştır.

İklim değişikliği orman kaynaklarını olumsuz düzeyde etkileyecektir. $\mathrm{Bu}$ etkilere, biyolojik çeşitlilik kaybı ve dolayısıyla ekosistem hizmetlerinin sekteye uğraması, orman sağlığı ve verimliliğindeki değişiklikler ve bazı türlerin coğrafi dağılımlarındaki değişiklikler örnek olarak verilebilir. $\mathrm{Bu}$ etkilerin üstesinden gelmek için ormancılık yönetim ve uygulamalarında değişiklik yapılması gerekmektedir (Sousa-Silva vd., 2018). Ormancılıkta uyum, iklim değişikliği odağını içeren sürdürülebilir orman yönetimi olup iklim değişikliğine uyum stratejileri, sürdürülebilir orman yönetim planlarının bir risk yönetimi bileşeni olarak görülebilir (Spittlehouse ve Stewart, 2003). Uyum önlemlerinin geliştirilmesi aciliyet arz etmektedir. Çünkü gençleştirilen veya ağaçlandırmalarla oluşturulan ormanlar, idare süresi boyunca büyük ölçüde değişebilecek iklim koşullarıyla başa çıkmak zorunda kalacaktır (Kolström vd., 2011).

Türkiye'nin 2011-2023 yıllarını kapsayan “İklim Değişikliği Uyum Stratejisi ve Eylem Planı”nda, ekosistem hizmetleri, biyolojik çeşitlilik ve ormancılık başlığı altında aşağıda gösterilen öncelikli hedefler/alt hedefler belirlenmiştir (ÇŞB, 2011);

1. İklim değişikliğine uyum yaklaşımının ekosistem hizmetleri, biyolojik çeşitlilik ve ormancılık politikalarına entegre edilmesi

- Mevcut stratejilerin iklim değişikliği etkilerine uyum için gözden geçirilmesi

2. İklim değişikliğinin biyolojik çeşitlilik ve ekosistem hizmetleri üzerindeki etkilerinin belirlenmesi ve izlenmesi

- İklim değişikliğinin orman alanlarındaki türler üzerine etkileri açısından tespiti ve izlenmesi

- Orman alanlarında iklim değişikliğinin etkilerinden kaynaklanan arazi kullanım değişiminin tespit edilmesi

- Orman ekosistemlerinin sağlığının izlenmesi

- Korunan alanlarda iklim değişikliğinin etkilerini belirleme ve izlemeye yönelik araştırma ve geliştirme çalışmalarının yapılması

- Orman köylülerinin sosyo-ekonomik kalkınmasında iklim değişikliğine uyum faaliyetlerinin dikkate alınması ve bu yolla kırsal kalkınmaya destek olunması

- Dağ, step, iç su, deniz kıyı ekosistemlerinde ve sağladıkları ekosistem hizmetlerinde iklim değişikliği etkilerinin belirlenmesi, izlenmesi, iklim değişikliğine uyuma yönelik önlemlerin geliştirilmesi

- Deniz ve kıyı alanları yönetimi çerçevesine iklim değişikliğine uyumun entegre edilmesi

- Ormanların yangınlara karşı korunması.

Yukarıda belirlenen hedeflere göre ormancılık politikalarında uyum süreçlerinin yönetimi için değişikliklerin yapılması gerektiği ve henüz iklim değişikliğinin biyolojik çeşitlilik ve ekosistem hizmetleri üzerindeki etkilerinin tam olarak belirlenemediği görülmektedir. 2019-2023 yıllarını kapsayan “Orman Genel
Müdürlüğü Stratejik Planı" incelendiğinde stratejik amaç ve hedeflerin bir kısmı iklim değişikliğine uyum ile ilişkilidir (OGM, 2018). Yine Ulusal Ormancilik Programı, 11. Kalkınma Planı ve Ormancılık Özel İhtisas Komisyon Raporu'nda orman kaynaklarının iklim değişikliğine uyumu konusunda hedef ve eylemlere yer verilmiştir. Bunun yanında yerel düzeyde de iklim değişikliğine uyum kapsamında çalışmalar yürütülmektedir (Zeydanlı vd., 2010). Görüldüğü üzere iklim değişikliğine uyum süreçlerinin henüz başında olduğumuzu belirtmek gerekir. $\mathrm{Bu}$ makalede orman kaynakları yönetiminin iklim değişikliğine uyum süreçlerine yönelik orman mühendislerinin alg1 ve görüşleri belirlenmiş, iklim değişikliğine yönelik bilgi düzeyleri, iklim değişikliğinin orman kaynaklarına etkileri ve uyum süreçleri kapsamında mevcut ve öngörülen ormancılık yönetim ve uygulamaları değerlendirilmiştir.

\section{Materyal ve yöntem}

Çalışmada veriler anket yoluyla toplanmıştır. Anket formlarının tasarımında Sousa-Silva vd. (2018) ve Peterson St-Laurent vd. (2018)'den de faydalanılmıştır. Anket formunun ilk bölümünde iklim değişikliğine yönelik bilgi düzeyi, iklim değişikliğinin orman kaynakları üzerine etkileri ve iklim değişikliğine uyum kapsamında ormancılık yönetim ve uygulamalarının değerlendirilmesine yönelik soru ve ifadelere yer verilmiştir. İkinci bölümde ise anket çalışmalarına katılan orman mühendislerin profil özelliklerinin belirlenmesine yönelik sorular yer almıştır. Hazırlanan anket formlarının uygulanabilmesi için Isparta Uygulamalı Bilimler Üniversitesi Bilimsel Araştırma ve Yayın Etiği Kurulunun 26.10.2020 tarih ve 33/01 nolu kararı ile etik kurul izni alınmıştır. Anket formunda yer alan ölçekli ifadelere yönelik iç tutarlılık katsayısı (Cronbach alfa değeri) 0,803 olarak bulunmuş olup 0,8 değerinden büyük olduğu için kullanılan ölçeğin istatistiki olarak yüksek güvenilirlikte olduğu görülmektedir (Kılıç, 2016).

Son hali verilen anket formlarının uygulanması için örnek büyüklüklerinin belirlenmesinde sınırlı toplumlarda kullanılan ve aşağıda açıklanan eşitlikten (1) faydalanılmıştır (Baş, 2010);

$$
n=\frac{N t^{2} p q}{d^{2}(N-I)+t^{2} p q}
$$

\section{Burada;}

n: Örnek büyüklüğünü,

t: Belirli bir anlamlllık düzeyinde $\mathrm{t}$ tablosuna göre bulunan teorik değer (\%95 güven düzeyi için 1.96),

$\mathrm{N}$ : Ana kütle büyüklüğünü,

p: Ölçmek istenilen büyüklüğün ana kütlede bulunma olasılığını (0.5),

q: Ölçmek istenilen büyüklüğün ana kütlede bulunmama olasılığını $(0.5)$,

$\mathrm{d}$ : Kabul edilen örnekleme hatasını (Bu çalışmada \%7 olarak alınmıştır) göstermektedir.

Yukarıdaki formüle göre hesaplanan örnek büyüklüğü, asgari 194 kişi olarak belirlenmiş olup, 241 orman mühendisi anket çalışmalarına katılmıştır. Anket çalışmaları ile elde edilen veriler, SPSS 22 paket programı kullanılarak ilk aşamada yüzdelik oranlara dönüştürülmüştür. Anket verilerinin parametrik veri olup olmadığ 1 Shapiro-Wilk testi ile araştırılmış ve \%95 güven düzeyinde verilerin normal 
dağılıma sahip olmadığı $(\mathrm{p}<0,05)$ yani parametrik olmadığı belirlenmiştir. Bundan dolayı ki-kare testi ile orman mühendislerinin verdikleri yanıtların, profil özelliklerine (cinsiyet, yaş, görev yıll, eğitim düzeyi ve görev yapılan sektöre) göre farklı olup olmadığı analiz edilmiştir.

\section{Bulgular ve tartışma}

\subsection{Orman mühendislerinin profili}

Anket çalışmalarına katılan orman mühendislerine ilişkin cinsiyet, yaş, görev y1lı, eğitim düzeyi ve görev yapılan sektörlere ilişkin bilgiler Çizelge 1'de gösterilmiştir. Cinsiyet bakımından yapılan değerlendirmelere göre katılımcıların yaklaşık \%80'i erkektir. Çalışmaya katılan mühendislerin \%61,8'i 26-45 yaş aralığındadır. Görev yılları bakımından 20 yıldan fazla süredir görev yapanların oranı yaklaşık $\% 35$ ile ilk sırada, 1-5 yıl arası görev yapanlar ise ikinci sıradadır. Anket çalışmalarına katılan orman mühendislerinin \%40'tan fazlası lisansüstü eğitimi tamamlamış durumdadır. Katılımcıların yarısından fazlası ormancılık ile ilgili kamu sektöründe görev yapmaktadır.

\section{2. İklim değişikliğine yönelik bilgi düzeyi}

Orman mühendislerine yöneltilen "iklim değişikliğ $i$ denilince aklınıza ilk gelen kavram hangisidir?” sorusuna verilen yanıtlara göre, ilk üçte sırasıyla doğal dengenin bozulması, küresel 1sınma ve mevsim değişikliği kavramları yer almaktadır. Yağışların azalması, çevre kirliliği, kış mevsiminin yaşanmaması ve hava şartlarının bozulması kavramları ise iklim değişikliğini tanımlamak için daha düşük düzeyde tercih edilmektedir (Şekil 1). İklim değişikliğine yönelik kamuoyu algılarının belirlenmesi amacıyla yapılan çalışmalarda da benzer kavramlar öne çıkmıştır (Gülsoy ve Korkmaz, 2020; Korkmaz, 2018; Şen ve Özer, 2018; Steenjes vd., 2017; Demirkaya, 2008). Görüldüğü üzere iklim değişikliği farkındalığı daha çok gözlenebilir değişikliklerin etkisi ile oluşmaktadır. Lujala vd. (2015) bu durumu, duygusal ve deneyime dayalı öğrenmenin, entelektüel temelli öğrenmeye göre daha etkili olması ile açıklamaktadır. Ancak belirtilen çalışmaların aksine bu çalışmada doğal dengenin bozulması ilk sırada yer almıştır. Bunun en önemli nedeni çalışma evreninin doğal kaynak yöneticileri konumunda olan orman mühendislerinden oluşması ile açıklanabilir.

İklim değişikliğine yönelik bilgi düzeylerinin ölçümü önemlidir. Çünkü iklim değişikliğinin etkilerini azaltma ve uyum süreçlerinin başarısı, bu konulardaki bilgi düzeyi ile ilişkilidir. Farklı toplum kesimlerini ele alan çalışmalarda, iklim değişikliğine yönelik bilgi düzeylerinin düşük veya istenilen seviyede olmadığı sonucuna ulaşılmıştır (Gülsoy ve Korkmaz, 2020; Alkan ve Özçelik, 2019; Korkmaz, 2018; Ochieng ve Koske, 2013; Semenza vd., 2008; Michail vd., 2007; Papadimitriou, 2004). Orman mühendisleri, iklim değişikliği ile mücadele ve uyum ile iklim değişikliğinin hayatımıza etkileri konularında bilgi düzeylerinin yeterli olduğunu belirtmektedir (Şekil 2). Ancak karbon ayak izi konusunda ise bilgi düzeyi göreli olarak düşüktür. Karbon ayak izi, birim karbondioksit cinsinden ölçülen, kurum veya bireylerin ulaşım, ısınma, elektrik tüketimi vb. faaliyetlerinden kaynaklanan toplam sera gazı salım miktarı olup bireysel karbon salımının yönetimi açısından önemli bir kavramdır (Ekici, 2019).
İklim değişikliğinin nedenleri ile ilgili verilen yanıtlar incelendiğinde (Şekil 3), en önemli üç neden sırasıyla; sera gazlarındaki artış, ormansızlaşma ve endüstrileşme olarak sıralanmaktadır. Bu yanıtlar sera gazları salımının azaltılması ve karbon tutulumu sayesinde iklim değişikliğinin etkilerinin azaltılmasında karasal ekosistemler arasında hayati öneme sahip olan orman kaynaklarının korunması gerekliliği görüşünü ortaya koyması bakımından önemlidir.

Çizelge 1. Anket çalışmalarına katılan orman mühendislerine ilişskin bazı bilgiler

\begin{tabular}{lrr}
\hline Cinsiyet & Sayı & $\%$ \\
\hline Kadın & 50 & 20.7 \\
Erkek & 191 & 79.3 \\
\hline Yaş Grupları & Sayı & $\%$ \\
\hline$\leq 25$ & 17 & 7.1 \\
$26-45$ & 149 & 61.8 \\
$46-65$ & 75 & 31.1 \\
\hline Görev y1lı & Say1 & $\%$ \\
\hline $1-5$ yıl & 75 & 31.1 \\
$6-10$ yıl & 30 & 12.5 \\
$11-15$ yıl & 26 & 10.8 \\
$16-20$ yıl & 27 & 11.2 \\
$>20$ yıl & 83 & 34.4 \\
\hline Eğitim düzeyi & Say1 & $\%$ \\
\hline Lisans & 141 & 58.5 \\
Yüksek lisans & 52 & 21.6 \\
Doktora & 48 & 19.9 \\
\hline Görev yapılan sektör & Say1 & $\%$ \\
\hline Ormancılık ile ilgili kamu sektörü & 128 & 53.1 \\
Üniversite & 62 & 25.7 \\
Ormancilık ile ilgili özel sektör & 26 & 10.8 \\
Diğer (özel sektör) & 16 & 6.7 \\
Diğger (kamu) & 9 & 3.7 \\
\hline
\end{tabular}

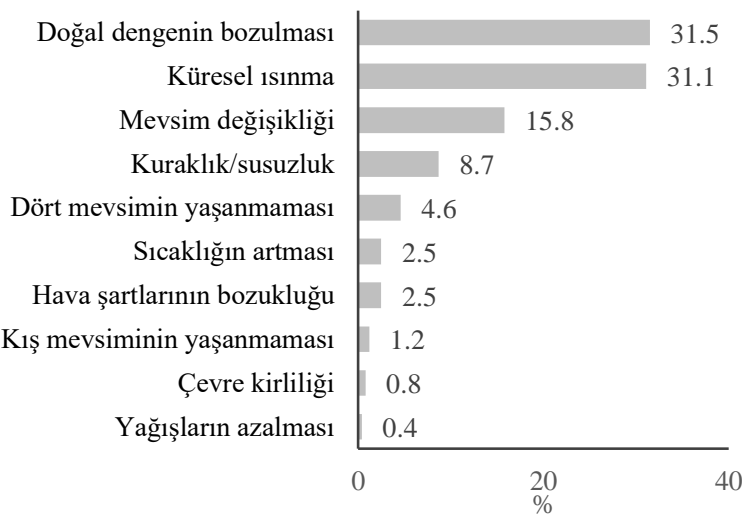

Şekil 1. İklim değişikliğini tanımlamak için ilk akla gelen kavramların dağılımı 
İklim değişikliğinin sonuçlarına yönelik değerlendirmelere göre (Şekil 4) iklim değişikliği nedeniyle orman yangınlarının sayısı, şiddeti ve yanan alan miktarı artacaktır. Ayrıca iklim değişikliği deniz seviyesinin yükselmesinde, şiddetli yağış sıklığının artışında, tatlı su kaynaklarının azalmasında, buzulların erimesinde, kuraklıkların artmasında ve sicaklıkların mevsim normallerinin üzerinde seyretmesinde etkili olarak görülmektedir. Ankete katılan orman mühendislerinin \%90.9'u iklim değişikliğini yüksek düzeyde endişe verici olarak değerlendirerek bu durumu desteklemektedir. Bununla birlikte iklim değişikliğinin sonuçları ile ilgili olarak orman mühendislerinin \%14.1'inin deniz seviyelerinin yükselmesi, \%10.8'inin şiddetli yağış sıklığının artması, \%10.4'ünün tatlı su kaynaklarının azalması ve \%8.3'ünün ise orman yangınlarının sayısı, şiddeti ve yanan alan miktarının artması konularında kararsız oldukları görülmektedir.

Katılımcılar tarafından "iklim değişikliğinin neden olduğu şeklinde yorumladığınız herhangi bir aşırı hava olayı yaşadınız mı?" sorusuna $\% 83.4$ oranında evet yanıtı verilerek bu olaylar arasında ilk üç sırada; yaz sıcaklıklarında artış, kuraklık ve kış soğuklarında azalma olduğu belirtilmektedir (Şekil 5). Sousa-Silva vd. (2018) tarafindan yapılan çalışmada ise kuvvetli rüzgar ve firtınalar ilk sırada yer alırken bunu, kuraklık ve yaz sıcaklıklarındaki artışlar izlemiştir.

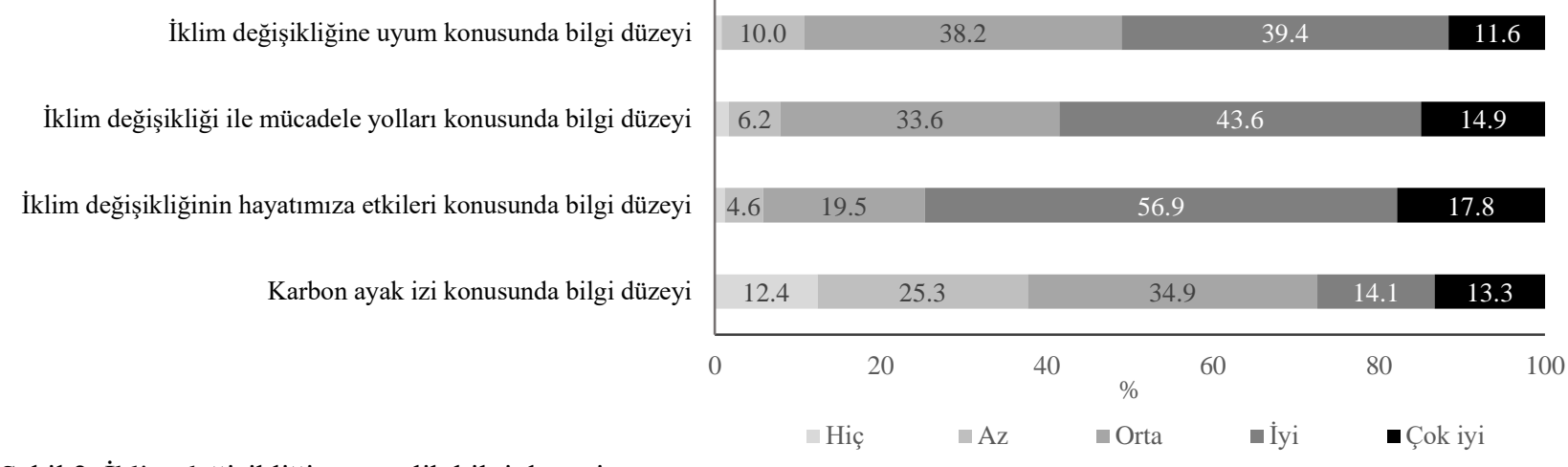

Şekil 2. İklim değişikliğine yönelik bilgi düzeyi

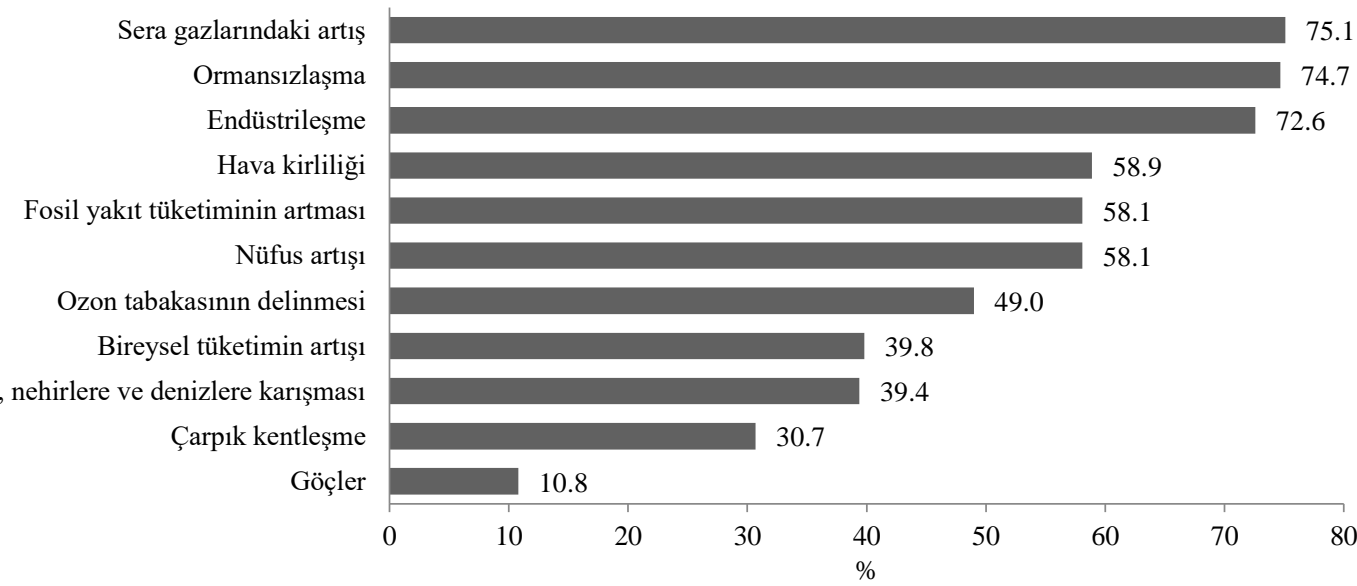

Şekil 3. İklim değişikliğinin nedenleri (Birden fazla seçenek işaretlemiş̧tir)

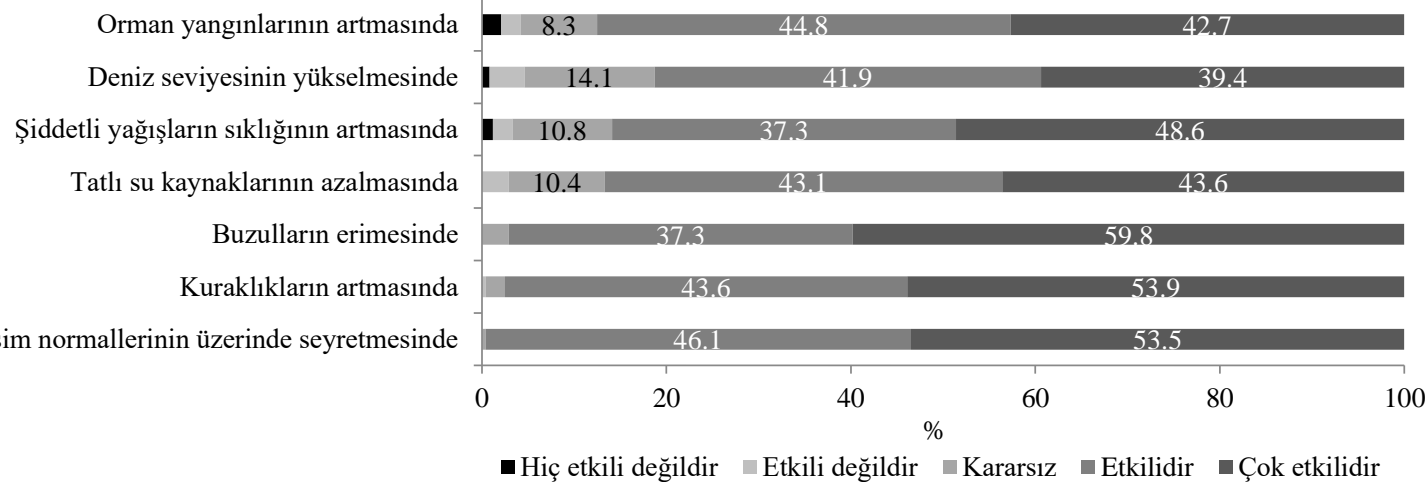

Şekil 4. İklim değişikliğinin sonuçları 


\section{3. İklim değişikliğinin ormanlar üzerindeki etkisine yönelik görüşler}

Orman mühendislerinin \%91.7'si değișen ölçeklerde (Çok iyi derecede: \%30.7; İyi derecede: \%44.0; Orta düzeyde: \%17.0) iklim değişikliğinin ülkemiz ormanları üzerindeki olası etkileri hakkında bilgiye sahiptir. Benzer şekilde iklim değişikliğini azaltmak için ülkemiz ormanlarının yönetim stratejileri hakkında bilgi sahibi olanların oranı (Çok iyi derecede: \%36.9; İyi derecede: $\% 37.4$; Orta düzeyde: \%20.3) \%94.6 ile yüksek düzeydedir. Ki-kare testi sonuçlarına göre yaş grupları itibariyle verilen yanıtlar istatistiksel olarak anlamlı farklılık $(\mathrm{p}<0.05)$ arz etmekte olup yaş arttıkça bilgi düzeyi artmaktadır. 26 yaş altı mühendislerde iyi veya çok iyi düzeyde bilgi sahibi olanların oran $\% 52.9$ iken bu oran $26-45$ yaş grubunda $\% 71.1$ 'e, 46 65 yaş grubunda ise $\% 85.3$ 'e yükselmektedir.

İklim değişikliğinin orman kaynaklarına yönelik olası etkilerine ilişkin görüşler incelendiğinde (Şekil 6), abiyotik zararlar (orman yangını, kuraklık, şiddetli firtınalar vb.) ve entomolojik/fitopatolojik zararların artışı ve zamanla tür kompozisyonundaki değişimler ilk sıralarda yer almıştır. Belirtilen öncelikli etkiler yazın incelendiğinde yapılan çalışmalarla da uyumludur. 2021 yılı orman yangını-iklim değişikliği ilişkisinin en yoğun tartışıldığı yıl olmuştur. Çünkü özellikle Antalya ve Muğla illerinde meydana gelen ve yangın istatistiklerinin tutulmaya başlandığ 1937 yılından bugüne kadar en fazla alanın yanmasına neden olan orman yangınları bu yıl meydana gelmiştir. İklim değişikliğinin orman yangınları üzerine etkilerine yönelik olarak örneğin Türkeş ve Altan (2012), gözlenen ve kestirilen iklim değişikliği ve değişkenlikleri göz önünde bulundurularak yöneticiler tarafindan orman yangınlarının önlenmesine yönelik ulusal, bölgesel ve yöresel çözüm önerilerinin geliştirilmesi gerektiğini vurgulayarak bu duruma dikkat çekmiştir. Ayrıca yapılan bilimsel çalışmalarda iklim değişikliği ile böcek ve patojenlerden kaynaklanan zararlı riskinin artacağına yönelik tespitlere yer verilmektedir (IPCC Secretariat, 2021; Sarıkaya ve Şen, 2020; Sarıkaya vd., 2018; Şimşek vd., 2010). Tür kompozisyonlarına yönelik değişimlere ilişkin senaryo analizlerinde de değişimlerin olacağı hatta bazı türlerin yaşam alanlarının daralacağına ilişkin belirlemeler yapılmaktadır (Kıraç ve Ertuğrul, 2021; Babalık vd., 2021; Li vd., 2021; Briceño vd., 2020; Dagtekin vd., 2020; Akyol ve Orucu, 2019; Qin vd., 2017). Diğer değişimlere ilişkin oranlar Şekil 6'da görülmektedir.

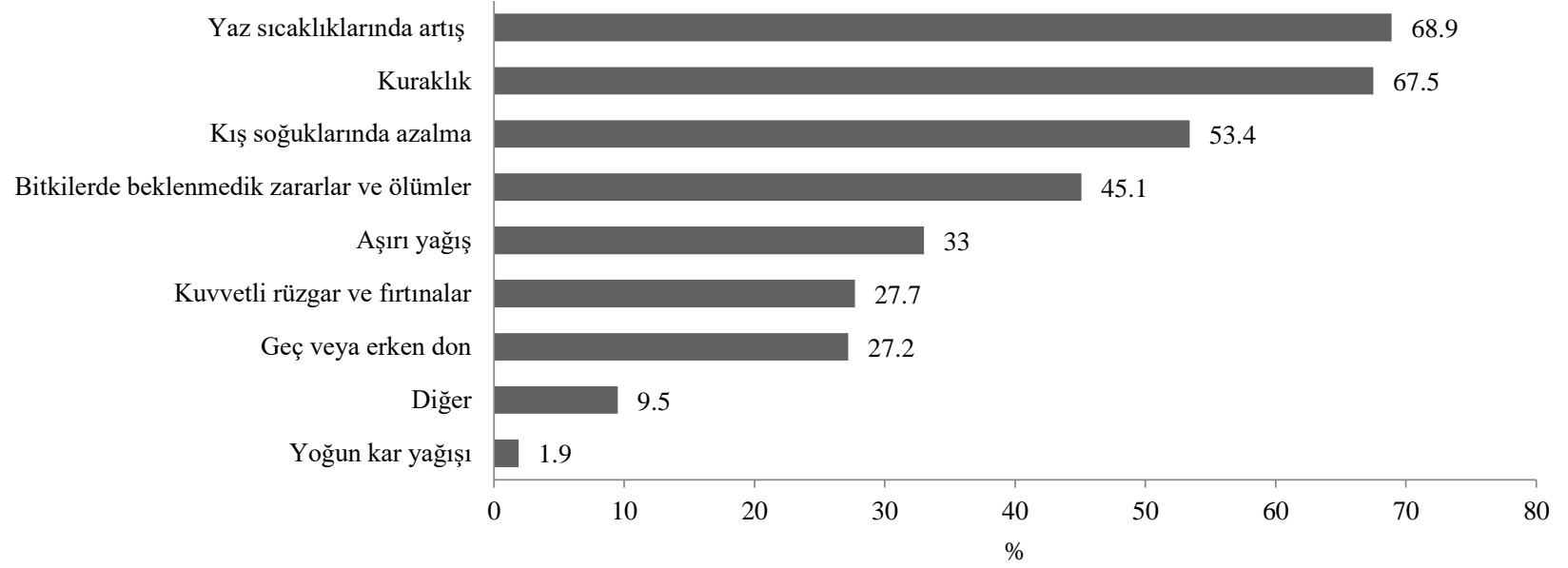

Şekil 5. İklim değişikliğinin neden olduğu hava olayları (Birden fazla seçenek işaretlemiştir)

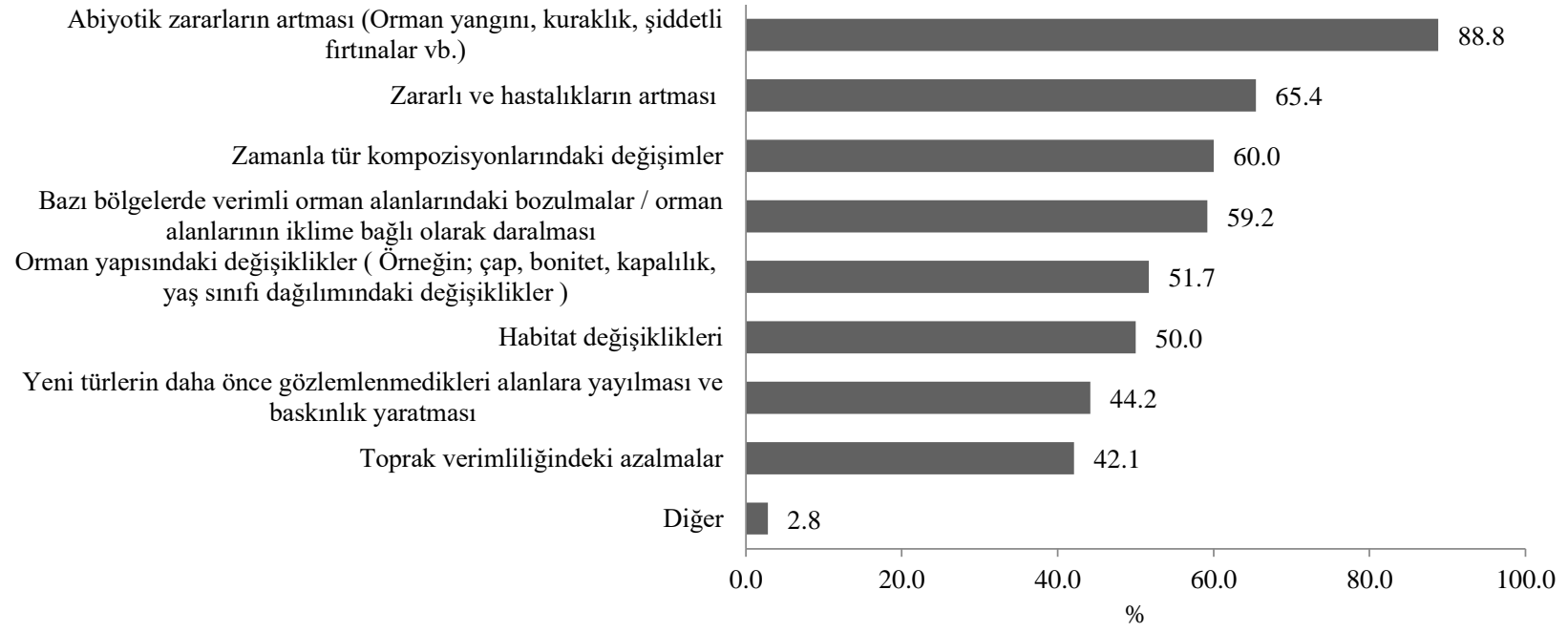

Şekil 6. İklim değişikliğinin ormanlara etkisine yönelik olası değişimler (Birden fazla seçenek işaretlemişstir) 
Genel olarak ormancılık politikalarının iklim değişikliğinin orman kaynakları üzerindeki olumsuz etkilerini önlemek için uygunluğu değerlendirildiğinde katılımcıların sadece \%5.8'i mevcut politikaların uygun olduğunu ve iyi bir şekilde uygulandığını belirtmiştir. Bu bulgu mevcut politikaların mevcut hali ile yeterli olmadığını ve/veya ormancılik uygulamalarına yeterli düzeyde aktarılamadığını ortaya koymuştur (Çizelge 2). Yaş grupları itibariyle verilen yanıtlar incelendiğinde (ki-kare, $\mathrm{p}<0.05)$ mevcut politikaların önemli ölçüde değişmesi gerektiğini belirtenlerin oranı $46-65$ yaş grubunda $\% 50.7$ iken $26-45$ yaş grubunda $\% 32.9$ ve 25 ve altı yaş grubunda \%23.5'e düşmektedir. Görev yapılan yıl itibariyle de benzer bulgulara ulaşılmıştır (ki-kare, $\mathrm{p}<0.05$ ). Eğitim düzeyine göre bir değerlendirme yapıldığında da verilen yanıtlar istatistiksel olarak farklılaşmaktadır (ki-kare, $\mathrm{p}<0.05)$. Buna göre lisans mezunu olan mühendisler arasında mevcut politikaları ve uygulamaları yeterli bulanların oran $1 \% 9.2$ iken yüksek lisans mezunu olanlarda bu oran \%1.9'a gerilemektedir. Doktora mezuniyetine sahip mühendislerin tamamı mevcut politikaları ve/veya uygulamaları yetersiz bulmaktadır. Bunun yanında mevcut politikaların önemli ölçüde değişmesi gerektiği konusunda lisans mezunlarının \%33.3'ü hem fikir iken bu oran yüksek lisans mezunlarında $\% 40.4$, doktora mezunlarında ise \%47.9'dur.

İklim değişikliğinin orman kaynakları üzerinde olumsuz etkilerinin yanında "iklim değişikliği sayesinde ormanların toplum nezdinde önemi artmaktadır" ifadesine \%85.5 oranında katılım sağlanmıştır. Yani daha önce de söz edildiği gibi toplumun iklim değişikliğinin nedenleri arasında ormansızlaşmayı görmesi ve iklim değişikliğinin etkilerinin azaltılmasında orman kaynaklarının hayati önem sahip olması, bu ifadeye katılım oranının yüksek çıkmasını açıklayabilmektedir.

\section{4. İklim değişikliğine uyum kapsamında ormancılık yönetim ve uygulamalarına ilişkin algılar ve görüşler}

Orman kaynakları yönetiminin iklim değişikliğine uyumunun henüz sağlanmadığını $(\% 42.3)$ ya da kısmen sağlandığını (\%44.8) düşünenlerin oranı \%87.1'dir. Yaş grupları itibariyle verilen yanıtlar istatistiksel olarak farklılaşmaktadır (ki-kare, $\mathrm{p}<0.05$ ). Buna göre 46-65 yaş grubunda uyumun sağlanmadığını belirtenlerin oranı $\% 54,7$ iken bu oran 26 yaş altı grubundaki mühendislerde \%17.6'ya gerilemektedir. Yani genç bireyler bu konuda daha olumlu yanıtlar vermiştir. Görev yapılan yıla göre de benzer bulgulara ulaşılmıştır (ki-kare, p<0.05). Cinsiyet itibariyle yapılan değerlendirmede de verilen yanıtlar farklılaşmaktadır (ki-kare, $\mathrm{p}<0.05$ ). Buna göre orman kaynakları yönetiminin iklim değişikliğine uyumunun sağlandığını düşünenlerin büyük bir bölümü erkek mühendislerdir. "İklim değişikliğine uyum için orman kaynaklarının yönetim biçimi değişmelidir" görüşüne sahip olanların oranı \%85.1 ile yüksek düzeydedir. Mühendislerin görev yaptıkları sektörler itibariyle bu soruya verilen yanıtlar istatistiksel olarak farklılaşmakta (ki-kare, $\mathrm{p}<0.05$ ) olup üniversitelerde görev yapan orman mühendislerinin bu soruya \%93.5 ve diğer özel sektör alanında görev yapan mühendislerin ise $\% 68.8$ oranında evet yanıtı vermiş olması bu farklılığın nedenidir. Britanya Kolumbiyası'nda yapılan bir araştırmada da uygulayıcı görüşlerine göre iklim değişikliğine uyum konusunda orman kaynakları yönetiminin sistem yaklaşımı çerçevesinde yeniden gözden geçirilmesi gerekliliği vurgulanmıștır (Nelson vd., 2016).

Orman kaynakları yönetiminin iklim değişikliğine uyumunun sağlanması için yapılması gerekenler hakkındaki görüşler Şekil 7'de görülmektedir. Öne çıkan ilk görüş; karışık meşcerelerin kurulmasının teşvik edilmesidir. Karışık meşcerelere genel ilgi son yıllarda artmıştır. Ancak karışık ormanların yönetimi, karışımların çevresel değişikliklere direnç ve uyumu ile topluma ekosistem hizmetlerinin sağlanmasındaki rolü konusunda bilgi düzeyi düşüktür (Coll vd., 2018).

Ağaçlandırmalarda gelecekteki iklime daha iyi uyum sağlayabilecek türlere yer verme bir diğer önemli görüştür. Zeydanlı vd. (2010)'a göre iklim değişikliği nedeniyle meşcerelerin içerisinde yer alan türler arasında baskınlık durumunun değişmesi veya komşu bölgelere geçiş daha sik karşılaşılabilecek bir durum olup bu özellikteki alanlarda gerçekleşen değişimleri desteklemek yerinde bir yaklaşım olacaktır.

Bir diğer önemli görüş orman sağlı̆̆ının izlenmesini sağlamaktır. Orman Genel Müdürlügü tarafından “Ormanlar Üzerine Hava Kirliliğinin Etkilerinin İzlenmesi ve Değerlendirilmesi Uluslararası İşbirliği Programı (ICP Forest)" kapsamında orman ekosistemlerinin sağlığının izlenmesine yönelik çalışmalar yürütülmektedir. Özellikle Seviye II alanlardaki otomatik meteorolojik gözlem istasyonu sayısının arttırılması, iklim modelleme çalışmaları kapsamında daha fazla noktadan veri alınmasının sağlanması, veri sayısının arttırılması ve karşılaştırılabilir sonuçlara ulaşma açısından önemlidir (Demir ve Şahin 2014). Ülkemizin sürdürülebilir orman yönetimi ölçüt ve göstergeler setinde 2018 yılından itibaren ormanların sağlığı, canlılığ 1 ve bütünlüğü ölçütü altında "ormanların hava kirliliği iklim değişikliği etkilerinin izlenmesi göstergesi yer almıştır (Hakverdi, 2020). Akyol ve Tolunay (2014) tarafindan yapılan çalışmada "Karbon ve Su Döngüsü" konusu sürdürülebilir orman yönetimi için ayrı bir ölçüt olarak önerilmiştir. 2018 yılındaki revizyonda gösterge niteliğinde yapılan düzenlemelerin gelecekte daha geniş kapsamlı ölçüt ve gösterge düzenlemelerinin yapılacağının bir işareti olarak yorumlanabileceğini göstermektedir.

Odun üretim hedeflerini küçültme, yeni korunan alanlar ilan etme, doğal ormanlarda üretimi sınırlandırma ve yaşlı ormanları koruma şeklinde öncelikle koruma odaklı yönetim seçenekleri de alınabilecek önlemler arasında yer almaktadır. Doğal gençleştirmeye ağırlık verme seçeneği de öne çıkmaktadır. Zeydanlı vd. (2010)'da benzer önlemlere çalışmalarında yer vermiştir.

Çizelge 2. Genel olarak, ülkemiz ulusal ormancılık politikalarının iklim değişikliğinin olumsuz etkilerini önlemek için uygunluğu

\begin{tabular}{lcc}
\hline Seçenekler & Sayı & Yüzde \\
\hline $\begin{array}{l}\text { Mevcut politikalar uygun ve iyi } \\
\text { uygulanıor. }\end{array}$ & 14 & 5.8 \\
$\begin{array}{l}\text { Mevcut politikalar uygun ancak yetersiz } \\
\text { uygulaniyor. }\end{array}$ & 37 & 15.3 \\
$\begin{array}{l}\text { Mevcut politikaların bazı yönleri ve } \\
\begin{array}{l}\text { uygulamaları iyileștirilmelidir. } \\
\text { Mevcut politikalar önemli ölçüde } \\
\text { değiştirilmelidir. }\end{array}\end{array}$ & 99 & 41.1 \\
\hline
\end{tabular}


Orman ekosisteminin direncini ve uyum kapasitesini arttırmak için, sadece ekolojik değil aynı zamanda bölgenin sosyal ve ekonomik dinamikleri de göz önünde bulundurularak önlemler geliştirilmelidir (Zeydanlı vd., 2010). Ülkemizde 2008 yılından itibaren orman amenajman planlarında "Ekosistem Tabanlı Fonksiyonel Planlama" esasına geçilmiş olması önemli bir gelişmedir. Bu kapsamda planlama aşamalarında katılımcılık esas olmalıdır. Spies vd. (2010), iklim değişikliğiyle başa çıkmak için etkili uyarlanabilir stratejilerin, sosyoekolojik bir sistem perspektifi gerektirdiğini ve ekolojik temelli orman kaynakları yönetimine geçişin, iklim değişikliği altında biyolojik çeşitliliğin korunması için iyi bir başlangıç noktası sağlayacağını belirtmektedir.

Orman kaynakları yönetiminin iklim değişikliğine uyumu kapsamında en önemli kısıt, teknik bilgi eksikliği olarak öne çıkmaktadır. Bunu önemli olduğuna dair inanç eksikliği ve mali açıdan yetersizlik izlemektedir (Şekil 8). Sousa-Silva vd. (2018) tarafindan yapılan çalışmada da iklim değişikliğine uyum eylemlerinin uygulamaya aktarılmasındaki en önemli engel, bilgi eksikliği olarak belirlenmiştir. Benzer şekilde Nelson vd. (2016)'da iklim değişikliğinin etkileri ve uyum konusundaki araştırmalara yönelik önemli kaynak aktarımlarına rağmen uygulayıcı düzeyinde önemli bilgi boşlukları olduğu belirtilmektedir. Orman kaynakları yönetiminin iklim değişikliğine uyumunu sağlamada en önemli dışsal destekler ise iklim değişikliği ve orman kaynakları üzerindeki etkileri konusunda toplumun bilinçlendirilmesi ve uyum sağlamaya yönelik politika ve mali teşvikler olarak belirlenmiştir.

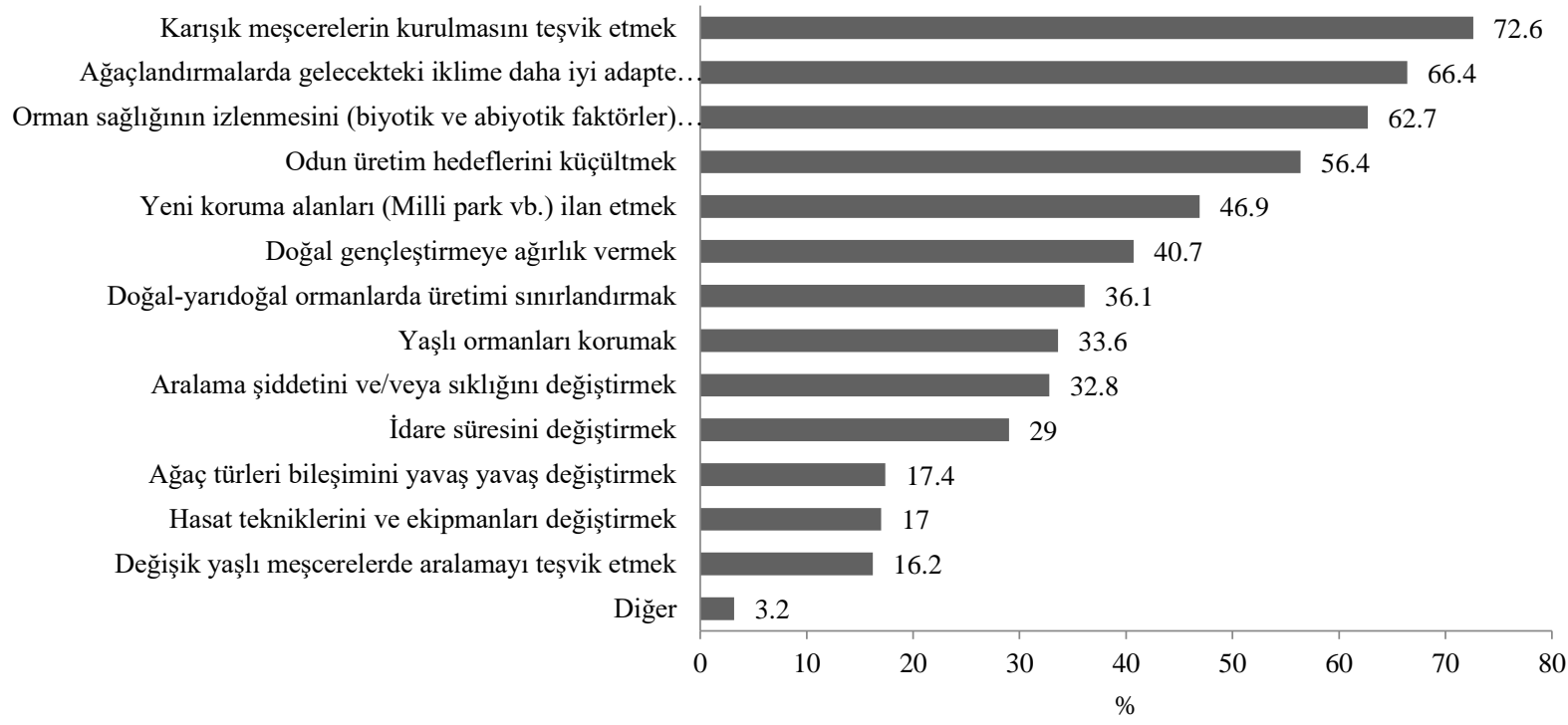

Şekil 7. Orman kaynakları yönetiminin iklim değişikliğine uyumunun sağlanması için yapılması gerekenler hakkındaki görüşler (Birden fazla seçenek işaretlemiştir)

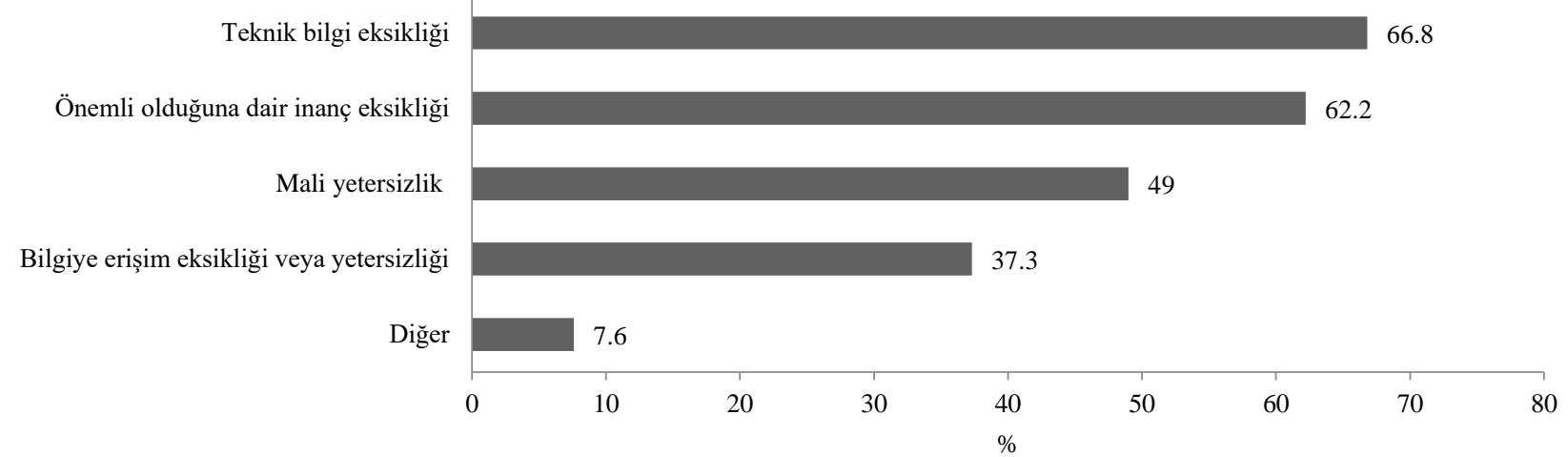

Şekil 8. İklim değişikliğine uyum eylemlerinin uygulamaya aktarılmasını sınırlayan en önemli kısıtlamalar (Birden fazla seçenek işaretlemiştir) 


\section{Sonuç ve öneriler}

İklim değişikliğinin orman kaynaklarına etkisine ilişkin olası değişimler; abiyotik ve biyotik zararların artacağı ve zamanla tür kompozisyonunda değişikliklerin yaşanacağ şeklindedir. $\mathrm{Bu}$ bağlamda orman kaynaklarının iklim değişikliğine karşı direncinin ve uyum kapasitesinin belirlenmesine yönelik çalışmaların yapılması önem arz etmektedir. Aynı zamanda bu değişimimler daha etkin bir biçimde izlenmeli ve değerlendirilmelidir.

Mevcut ulusal ormancılık politikaları iklim değișikliğinin olumsuz etkilerinin önlenmesi konusunda hem yetersiz bulunmuş hem de ormancılık uygulamalarına aktarımında sorunlar olduğu belirlenmiştir. İklim değişikliğinden etkilenme potansiyeli yüksek ormanlar için uygulama hedeflerinin belirlenmesi ve hedeflerin orman amenajman planlarına yansitılması gerekmektedir. Bu noktada ekosistem tabanlı fonksiyonel planlama bir firsat olarak değerlendirilebilir.

Bunun yanında iklim değişikliğine uyumun sağlanması için orman kaynakları yönetiminin değişmesi gerektiği görüşü büyük bir çoğunlukla ifade edilmiştir. Karışık meşcerelerin kurulmasının teşvik edilmesi, ağaçlandırmalarda gelecekteki iklime daha iyi uyum sağlayabilecek türlere yer verilmesi ve orman sağlığının izlenmesi en önemli önlemler olarak öne çıkmıştır. Ayrıca odun üretim hedeflerinin düşürülmesi, korunan alanların sayısının ve dolayısıyla alansal büyüklüğünün artırılması, doğal ormanlarda odun hammaddesi üretiminin sınırlandırılması ve yaşlı ormanların korunması diğer önlemler olarak belirlenmiştir. Görüldüğü üzere iklim değişikliğine uyum konusunda koruma odaklı yönetim seçenekleri de öne çıkmaktadır.

İklim değişikliğinin etkilerinin azaltılması, uyum ve yaşamsal etkileri konusunda orman mühendislerinin büyük bir bölümü yeterli düzeyde bilgi sahibi olduğunu belirtmiştir. İklim değişikliğinin nedenleri ve sonuçları ile ilgili ifadelere verilen yanıtlar değerlendirildiğinde de bilgi düzeyinin yeterli olduğu anlaşılmaktadır. Genel olarak orman mühendislerinin iklim değişikliğine yönelik endişe duymaları ve iklim değişikliği ile ilgili hususları orman kaynakları yönetimine dahil etme ihtiyaçlarının farkında olmaları önemlidir. Ancak orman kaynakları yönetiminin iklim değişikliğine uyumu konusunda teknik bilgi eksikliği en önemli kısıttır. Bu açıdan belirtilen bilgi eksikliklerinin giderilmesine yönelik çalışmalar ve ormancılık sektörü çalışanlarının iklim değişikliğine uyum konusundaki farkındalık ve bilgi düzeyinin artırılmasına yönelik programlar önemsenmelidir.

Gerek kamuoyu algılarını belirlemeye yönelik yapılan ve daha önce söz edilen bilimsel araştırmalarda iklim değişikliğinin nedenleri arasında ormansızlaşmanın gösterilmesi, gerekse bu çalışma kapsamında orman mühendislerinin iklim değişikliği sayesinde ormanların toplum nezdinde öneminin artacağı algısına sahip olmaları uyum kapsamında bir firsat olarak görülmelidir. Çünkü orman kaynakları yönetiminin iklim değişikliğine uyumunu sağlamada en önemli dişsal destek, iklim değişikliği ve orman kaynakları üzerindeki etkilerine yönelik toplumun bilinç düzeyinin artırılmasıdır. $\mathrm{Bu}$ bağlamda iklim değişikliğine yönelik kamuoyunun bilgi düzeyinin yeterli olmadığı değerlendirilmeli, öncelikle bilgi ardından da bilinç seviyesini artırmaya yönelik çalışmaların yapılması ile bu dışsal destekten daha yüksek düzeyde faydalanılmalıdır.

\section{Açıklama}

$\mathrm{Bu}$ makalede, Isparta Uygulamalı Bilimler Üniversitesi, Lisansüstü Eğitim Enstitüsü, Orman Mühendisliği Anabilim Dalında yürütülmekte olan "Ormancllı Sektöründe İklim Değişikliğine Yönelik Algılar ve İklim Değişikliği ile Mücadele ve Uyum Önlemlerinin Önceliklendirilmesi” başlıklı yüksek lisans tezinin verileri kullanılmıştır.

\section{Kaynaklar}

Akyol, A., Orucu, O.K., 2019. Investigation and evaluation of Stone Pine (Pinus pinea $\mathrm{L}$.) current and future potential distribution under climate change in Turkey, Cerne, 25:415 423.

Akyol, A., Tolunay, A., 2014. Sürdürülebilir orman yönetimi ölçüt ve göstergelerinin Türkiye için modellenmesi. SDÜ Orman Fakültesi Dergisi, 15: 21-32.

Alkan, H., Özçelik, R., 2019. A research on awareness of climate change and environmental issues. International Conference on Climate Change and Forestry, 12-15 November, Antalya, Turkey, pp. 88-97.

Babalık, A.A., Sarikaya, O, Orucu, O.K., 2021. The Current and future compliance areas of Kermes Oak (Quercus coccifera $\mathrm{L}$.) under climate change in Turkey. Fresenius Environmental Bulletin, 30(01): 406-413.

Baş, T., 2010. Anket. Seçkin Yayıncılık, Altıncı Baskı, Ankara.

Briceño, N.R., Sánchez, D.C., Castillo, E.B., Gurbillón, M.B., Sarmiento, F., Sotomayor, D., Oliva, M., López, R.S., 2020. Current and future distribution of five timber forest species in Amazonas, Northeast Peru: Contributions towards a restoration strategy. Diversity, 12:305.

Coll, L., Ameztegui, A., Collet, C., L€of, M., Mason, B., Pach, M., Verheyen, K., Abrudan, I., Barbati, A., Barreiro, S., Bielak, K., Bravo-Oviedo, A., Ferrari, B.,Govedar, Z., Kulhavy, J., Lazdina, D., Metslaid, M., Mohren, F., Pereira, M., Peric, S., Rasztovits, E., Short, I., Spathelf, P., Sterba, H., Stojanovic, D., Valsta, L.,Zlatanov, T., Ponette, Q., 2018. Knowledge gaps about mixed forests: What do European forest managers want to know and what answers can science provide? For. Ecol. Manag. 407: $106 \mathrm{e} 115$.

ÇŞB, 2011. Türkiye'nin İklim Değişikliği Uyum Stratejisi ve Eylem Planı (2011-2023). Cevre ve Sehircilik Bakanlığı, Ankara.

Dagtekin, D., Şahan, E.A., Denk, T., Köse, N., Dalfes, H.N., 2020. Past, present and future distributions of Oriental beech (Fagus orientalis) under climate change projections. PLoS ONE 15 (11): e0242280.

Demir, M., Şahin, U., 2014. Hava kirliliğinin ormanlar üzerindeki etkilerinin değerlendirilmesi ve izlenmesi hakkında Uluslararası İşbirliği Programı (ICP Forests), meteorolojik ölçümler. II. Ulusal Akdeniz Orman ve Çevre Sempozyumu, 22-24 Ekim, Isparta, s. 380-391.

Demirkaya, H., 2008. Sınıf öğretmeni adaylarının küresel ısınma kavramı algılamaları ve öğrenme stilleri: Fenomenografik bir analiz. Kuram ve Uygulamada Eğitim Bilimleri Dergisi, 8(1): 33-58.

Ekici, M., 2019. İklim değişikliğine direnç: Yerküre için karbon detoksu (Karbon Arınımı). Dirençlilik Dergisi, 3(2): 113-125.

Gülsoy, E., Korkmaz, M., 2020. Üniversite öğrencilerinin sosyoekonomik özelliklerinin küresel ısınma ve iklim değişikliği algıları üzerine etkileri. Turkish Journal of Forestry, 21(4): 428437.

Hakverdi, A.E., 2020. Türkiye'de sürdürülebilir orman yönetimi kriter ve göstergelerinin değerlendirilmesi. Turkish Journal of Forestry, 21 (3): 332-343.

IPPC Secretariat, 2021. Scientific review of the impact of climate change on plant pests - A global challenge to prevent and mitigate plant pest risks in agriculture, forestry and ecosystems. Rome. FAO on behalf of the IPPC Secretariat.

Kılıç, S., 2016. Cronbach'ın alfa güvenirlik katsayısı. Journal of Mood Disorders, 6(1): 47-48. 
Kıraç, A., Ertuğrul, E., 2021. Maskeli örümcek kusunun (Lanius nubicus, Licthenstein 1823) iklim değişimi etkisi altındaki dağılımı. Journal of Anatolian Environmental and Animal Sciences, 6 (2):245-251.

Kolström, M., Lindner, M., Vile'n, T., Maroschek, M., Seidl, R., Lexer, M.J., Netherer, S., Kremer, A., Delzon, S., Barbati, A., Marchetti, M., Corona, P., 2011. Reviewing the science and implementation of climate change adaptation measures in European Forestry. Forests, 2:961-982.

Korkmaz, M., 2018. Public awareness and perceptions of climate change: differences in concern about climate change in the West Mediterranean Region of Turkey. Applied Ecology and Environmental Research, 16(4):4039-4050.

Li, J., Fan, G., He, Y., 2021. Predicting the current and future distribution of three Coptisherbs in China under climate change conditions, using the MaxEnt model and chemical analysis. Science of The Total Environment, 698:134141.

Lujala, P., Lein, H., Rød, J.K., 2015. Climate change, natural hazards, and risk perception: The role of proximity and personal experience. Local Environment, 20(4): 489-509.

Michail, S., Atamou, A.G., Stamou, G.P., 2007. Greek primary school teachers' understanding of current environmental issues: An exploration of their environmental knowledge and images of natüre. Science Education, 91(2): 244-259.

Nelson, H.W., Williamson, T.B., Macaulay, C., Mahony, C., 2016. Assessing the potential for forest management practitioner participation in climate change adaptation. For. Ecol. Manag., 360:388-399.

Ochieng, M.A., Koske, J., 2013. The level of climate change awareness and perception among primary school teachers in Kisumu Municipality, Kenya. International Journal of Humanities and Social Science, 3(21):174-179.

OGM, 2018. Orman Genel Müdürlüğü Stratejik Plan (2019-2023). Orman Genel Müdürlüğü, Ankara.

Papadimitriou, V., 2004. Prospective primary teachers' understanding of climate change, greenhouse effect, and ozone layer depletion. Journal of Science Education and Technology, 13(2): 299-307.

Peterson St-Laurent, G., Hagerman, S., Kozak, R., Hoberg, G., 2018. Public perceptions about climate change mitigation in British Columbia's forest sector. PLoS ONE 13(4): e0195999.

Qin, A., Liu, B., Guo, Q., Bussmann, R.V., Ma, F., Jian, Z., Xu, G., Pei, S., 2017. Maxent modeling for predicting impacts of climate change on the potential distribution of Thuja sutchuenensis Franch., an extremely endangered conifer from southwestern China Glob. Ecol. Conserv., 10: 139-146.

Sarıkaya, O., Şen, İ., 2020. Estimation to current and future potential distribution areas of Pityogenes calcaratus (Eichhoff) in Turkish Forests, International Journal of Agriculture, Forestry and Fisheries, 8(4):118-122.

Sarıkaya, O., Karaceylan, İ.B., Şen, İ., 2018. Maximum entropy modeling (maxent) of current and future distributions of Ips mannsfeldi (Wachtl, 1879) (Curculionidae: Scolytinae) in Turkey. Applied Ecology and Environmental Research, 16(3): 2527-2535.
Semenza, J.C., Hall, D.E., Wilson, D.J., Bontempo, B.D., Sailor, D.J., George, L.A., 2008. Public perception of climate change: Voluntary mitigation and barriers to behavior change. American Journal of Preventive Medicine, 35(5):479-487.

Silkin, H., 2014. İklim değişikliğine uyum özelinde baz uygulamaların Türkiye açısından değerlendirilmesi. Orman ve $\mathrm{Su}$ İşleri Uzmanlık Tezi, Orman ve Su işleri Bakanlığı, Su Yönetimi Genel Müdürlüğü, Ankara.

Sousa-Silva, R., Verbist, B., Lomba, Â, Valent, P., Suškevics, M., Picard, O., et al., 2018. Adapting forest management to climate change in Europe: linking perceptions to adaptive responses. For. Policy Econ. 90:22-30

Spies, T.A., Giesen, T.W., Swanson, F.J., Franklin, J.F., Lach, D., Johnson, K.N., 2010. Climate change adaptation strategies for federal forests of the Pacific Northwest, USA: Ecological, policy, and socio-economic perspectives. Landscape Ecol., 25:1185-1199.

Spittlehouse, D.L., Stewart, R.B., 2003. Adaptation to climate change in forest management. BC Journal of Ecosystems and Management, 4(1):1-11.

Steentjes, K., Pidgeon, N., Poortinga, W., Corner, A., Arnold, A., Böhm, G., Mays, C., Poumadère, M., Ruddat, M., Scheer, D., Sonnberger, M., Tvinnereim, E., 2017. European perceptions of climate change (EPCC): Topline findings of a survey conducted in four European countries in 2016. Cardiff: Cardiff University.

Şen, G., Özer, Y.E., 2018. Üniversite öğrencilerinin iklim değişikliği ve çevre sorunları konusundaki farkındalıklarının değerlendirilmesi: Dokuz Eylül Üniversitesi Kamu Yönetimi örneği. Bitlis Eren Üniversitesi Sosyal Bilimler Enstitüsü Dergisi, 7(2): 667-688.

Şimşek, Z., Kondur, Y., Öner, N., Şimşek, M., 2010. Küresel iklim değişikliği dikkate alınarak kabukböceklerinin yönetimi. Kastamonu Üniversitesi Orman Fakültesi Dergisi, 10(1): 44-54.

Türkeş, M., 2008. Küresel iklim değişikliği nedir? Temel kavramlar, nedenleri, gözlenen ve öngörülen değişiklikler. İklim Değişikliği ve Çevre, 1:26-37.

Türkeş, M., Altan, G., 2012. Muğla Orman Bölge Müdürlüğü’ne bağlı orman arazilerinde 2008 yılında çıkan yangınların kuraklık indisleri ile çözümlenmesi. Uluslararası İnsan Bilimleri Dergisi, 9: 912-931.

Türkeş, M., Sümer, U.M. Çetiner, G., 2000. Küresel iklim değişikliği ve olası etkileri. Çevre Bakanlığı, Birleşmiş Milletler İklim Değişikliği Çerçeve Sözleşmesi Seminer Notları, 13 Nisan 2000, s.7-24.

Zeydanlı, U., Turak, A., Bilgin, C., Kınıkoğlu, Y., Yalçın, S., Doğan, H. 2010. İklim Değişikliği ve Ormancılık: Modellerden Uygulamaya. Doğa Koruma Merkezi, Ankara. 